\title{
Mania, CTCAE
}

National Cancer Institute

\section{Source}

National Cancer Institute. Mania, CT CAE. NCI Thesaurus. Code C143666.

A disorder characterized by excitement of psychotic proportions manifested by mental and physical hyperactivity, disorganization of behavior and elevation of mood. 